\title{
Trabalho e Reconhecimento entre Técnica, Política e Afetividade
}

\section{Work and Recognition between Technique, Politics and Affectivity}

\section{Trabajo y Reconocimiento entre Técnica, Política Y Afetividad}

\author{
Carolina Rodrigues Alves de Souza* \\ Universidade Federal Fluminense - UFF, Niterói, Rio de Janeiro, Brasil \\ Teresa Cristina Othenio Cordeiro Carreteiro** \\ Universidade Federal Fluminense - UFF, Niterói, Rio de Janeiro, Brasil
}

\begin{abstract}
RESUMO
Este artigo analisa o reconhecimento no trabalho. Trata-se de recorte de tese de doutorado em andamento que tem como campo os Centros de Referência Especializados da Assistência Social (CREAS) de Aracaju-SE, Brasil. Utilizando a psicossociologia como aporte teórico e metodológico, realizamos oficinas grupais com educadores sociais, psicólogos e assistentes sociais de três CREAS daquele município. A psicossociologia está atenta aos conflitos que surgem no contexto institucional e organizacional e às diversas modalidades de mal-estar que ali se instauram, favorecendo o olhar sócioclínico e a intervenção. Neste texto, discutiremos o trabalho no campo em questão atentando para sua função social e pensando-o enquanto via de acesso ou não ao reconhecimento social dos seus trabalhadores.
\end{abstract}

Palavras-chave: reconhecimento, trabalho, psicossociologia.

\begin{abstract}
On this paper we analyse the recognition at work. It refers to an extract of a $\mathrm{PhD}$ thesis which field work was developed at Center of Reference Specialized of Social Assistance (CREAS) in Aracaju-SE, Brasil. The psychossociology is the theoretical and methodological reference that supports the proposition of groups organized amongst professionals on the field of three CREAS, such as social educators, psychologists and social workers. The psychossociology discusses conflicts and the various forms of malaise in these contexts, where a socio-clinical regard and intervention are made possible. On this text we discuss the fieldwork paying attention to its social function, and also considering it as a device that gives access, or not, to social recognition.
\end{abstract}

Keywords: recognition, work, psychossociology.

\section{RESUMEN}

Este artículo analiza el reconocimiento del trabajo. Se trata de un recorte de tesis de doctorado en curso que tiene como campo los Centros de Referencia Especializados de la Asistencia Social (CREAS) de Aracaju-SE, Brasil. 
Apoyadas en la psicosociología como aporte teórico y metodológico, realizamos grupos con educadores sociales, psicólogos y asistentes sociales en tres CREAS. La psicosociología está actuando en los conflitos que surgen en el contexto institucional y organizacional y como múltiples modalidades de malestar que instaura, favoreciendo la análisis socioclínica y la intervención. Es sobre esta base que discutimos el trabajo en el campo de la asistencia social, atentando para su función social y pensando en él como vía de acceso o no al reconocimiento social de sus trabajadores.

Palabras clave: reconocimiento, trabajo, psicosociología.

O artigo analisa o reconhecimento no trabalho. Trata-se de um recorte de tese de doutorado em andamento ${ }^{1}$ que tem como campo os Centros de Referência Especializados da Assistência Social (CREAS) de Aracaju-SE, Brasil.

A psicossociologia, campo teórico da pesquisa, enfatiza o olhar sócioclínico na sua vinculação com o trabalho em instituições e organizações, favorecendo o estabelecimento de pontes com outros saberes clínicos em suas análises e investigações. Neste sentido teceremos pontes com outras clínicas do trabalho: a "Clínica da Atividade", representada especialmente por Yves Clot, a "Psicodinâmica do Trabalho", tendo como seu maior expoente Christophe Dejours, bem como a compreensão crítica do trabalho realizada pela Sociologia Clínica, com ênfase nas obras de Vincent de Gaulejac.

O objeto de pesquisa relaciona-se ao sentimento de mal-estar no trabalho inicialmente vivenciado pela primeira autora, psicóloga nesta política municipal, mas ganhou vulto ao identificá-lo em outros profissionais.

Os CREAS são equipamentos municipais da política de assistência social e promovem o atendimento a populações vulneráveis que vivenciam diversas violências físicas, psicológicas e patrimoniais. Tal política pública, instituída no país a partir do processo de redemocratização iniciado na década de 1980, tem como principal intuito o de prestar assistência social (como um dos eixos da seguridade social, em conjunto com a saúde e a previdência social) à população brasileira que vive em situação de extrema pobreza.

O município de Aracaju conta com quatro CREAS distritais. Em todos eles são executados os diversos serviços previstos na Politica Nacional de Assistência Social. De acordo com o território que abrangem, cada equipe se depara com demandas específicas, o que certamente interfere em seus modos de trabalho. Isso considerado, buscamos reunir trabalhadores dos CREAS em Aracaju a fim de compreender as problemáticas compartilhadas por eles, levando em consideração especialmente o que os aproxima, sem perder de vista, no entanto, as suas singularidades. 
A primeira parte do trabalho de pesquisa ocorreu nos quatro CREAS, com o dispositivo de observação participante, em novembro e dezembro de 2016. Solicitamos à gestão, com aquiescência das equipes, a inserção da pesquisadora nas reuniões de equipe. No ano seguinte, a pesquisadora tornou-se coordenadora de um dos CREAS, motivo pelo qual este foi retirado da investigação.

A segunda parte foi a sistematização das problemáticas levantadas a partir daquele primeiro momento, o que levou ao convite feito aos trabalhadores para participarem de oficinas, no total de 6 (seis) encontros. Estes foram integrados voluntariamente por 10 profissionais, que se mantiveram até o final, o que representa $21 \%$ do total dos profissionais.

A partir da escuta dos educadores sociais, psicólogos e assistentes sociais, buscamos compreender seus processos de trabalho e como eles vivenciam as exigências formais e subjetivas a respeito de suas atuações. Discutimos o trabalho vislumbrando sua função social, mas também pensando-o como via de acesso ou não ao seu reconhecimento social.

A problemática do reconhecimento no trabalho teve um atravessamento constante nas discussões. O enfoque, aqui, será em relação aos seus matizes vinculados aos papeis sociais dos trabalhadores, especialmente em seus vieses político e técnico.

o primeiro aparece desde o nível micropolítico associado a seus posicionamentos e decisões diárias, até o nível macro político, relacionado a questões da política municipal e suas repercussões no trabalho. O segundo é marcado por uma demanda constante de protocolos mais claros e por espaços de formação. Há a queixa quanto à imposição de modos de fazer muito hierarquizados e quanto à incompreensão do trabalho por parte dos que estão "acima" deles. Os sujeitos enfatizam ainda o caráter afetivo do papel do profissional, discutido essencialmente quanto à construção de vínculos junto às famílias dos usuários e entre eles.

\section{Lugar e valor do trabalho}

Hannah Arendt (1995) indica um processo de glorificação do trabalho ao afirmar que este passou a ser uma tarefa que atribui valor social ao cidadão ao deixar de ser uma atividade atribuída aos estratos menos valorizados socialmente. A autora aponta que tal glorificação transformou toda a sociedade em uma sociedade operária, que só compreende a busca da liberdade pela via do trabalho.

Para argumentá-lo, ela faz distinções entre labor, trabalho e ação. O primeiro é associado ao processo biológico do corpo humano e se refere à luta pela sobrevivência, e foi frequentemente relegado aos mais baixos estratos sociais, como aos escravos, que garantiam a 
sobrevivência dos outros estratos, destinados a funções tais quais as intelectuais, artísticas e políticas. O trabalho, por sua vez, corresponderia a certa mundanidade, ou seja, ao artificialismo da vida humana que, por sua via, deixa produtos que subsistem ao tempo em que foram realizados, ou seja, deixam heranças para os seres humanos por vir. A ação, por fim, seria a atividade que se exerce entre os homens sem a mediação da matéria, das coisas, guardando uma relação especial com a política, produzindo história (Arendt, 1995).

Arendt nos permite concluir sobre as possibilidades de reconhecimento do trabalho e da ação, estas indisponíveis no caso do labor, dado que ele se consome em si mesmo (Arendt, 1995). Assim, a discussão sobre o valor social do trabalho só existe quando ele deixa produtos e promove algo reconhecível socialmente. Poderíamos indicar, então, que aqueles trabalhos que se encerram em si mesmos não carregariam consigo grande reconhecimento social.

Neste ponto, resgatamos a discussão da psicossocióloga D. Lhuillier (2005) sobre o que ela denomina saleboulot, o trabalho sujo, a partir da tradução do conceito de dirtywork de E. C. Hughes. A autora aponta existirem, além de uma divisão do trabalho técnica e social, uma divisão moral e psicológica a partir da qual se definem os trabalhos mais ou menos valorizados. A construção de determinadas tarefas poderia ser identificada, portanto, em três níveis: o profissional, que remete à definição teórica do trabalho, à descrição das funções e às estruturas de formação, o nível do ofício (métier), que concerne às práticas reconhecidas e legitimadas pela comunidade profissional e os valores sustentados por ela e, por fim, o nível pessoal, que se traduz pelas modalidades diferenciadas de práticas e de uso de si no confronto cotidiano com os colegas de trabalho. $O$ trabalho sujo seria aquele que deve permanecer oculto: é durante uma greve de trabalhadores do lixo, por exemplo, que compreendemos haver ali um trabalhador, pois ele só passa a existir para nós quando falta (Lhuillier, 2005).

O exemplo torna mais clara a explicação, mas não resume o argumento: dada tal divisão moral, Lhuillier introduz um novo conceito, o de negativo psicossocial. Haveria algumas modalidades de trabalho que mantém relação - em um nível moral e psicológico com atividades e sujeitos aos quais não se deseja identificar e, da mesma maneira, prefere-se que permaneçam fora do campo de visão e de conhecimento. A autora esclarece que as profissões consideradas "sujas" servem a um papel específico, qual seja o de ocultar um viés social, o de preservar determinados pactos de negativos pela via da neutralização daqueles sujeitos que devem estar à margem (Lhuillier, 2009).

Tendo como referência os profissionais carcerários, seus sujeitos de pesquisa, a autora aponta que seria, portanto, seu papel o de evitar o 
contágio por aqueles que são seus objetos de trabalho. Isso os levaria a um esforço de diferenciação que explicaria sua atitude mais comum de tratá-los como objetos, implicando em um "imperativo menos institucional que uma necessidade psicológica" (Lhuillier, 2009, p. 47).

Lhuillier afirma ainda que o reconhecimento daqueles profissionais só pode se dar dentro da instituição, entre os pares, no trabalho partilhado. A preservação da clivagem por parte dos profissionais associados ao negativo psicossocial exige também a manutenção da ignorância, manifestada por uma intenção ativa de nada saber, uma recusa de conhecimento:

(...) quando o trabalho realizado, quando aquilo que cada um está convencido a fazer não é mais defensável aos seus próprios olhos, se instala um silêncio sobre o trabalho que é compreendido no seio das equipes. A vergonha isola. (...) A impossibilidade de se reconhecer no seu trabalho é uma questão mais essencial aqui que a falta de reconhecimento social. A delegação do <<trabalho sujo>> só se sustenta se os profissionais puderem subvertê-lo tornando esse trabalho estimável e realizando um <<bom trabalho>> (Lhuillier, 2009)

Carreteiro (2014) afirma que o ato de trabalhar se configura, contemporaneamente, em símbolo da formação pessoal dos indivíduos, central em sua constituição subjetiva (Carreteiro, 2014). Assim, é possível compreender o valor social do trabalho, a importância de se reconhecer como um membro ativo da sociedade. Não possuir trabalho ou possuir um que seja socialmente desprezado, faz com que o trabalhador se identifique com a figura do "inútil social", faltando-Ihe o reconhecimento social desejado (Carreteiro, 1999).

Já Honneth (2001) aponta o reconhecimento como um fato público que diz respeito à validade social, à confirmação social da sua existência. O reconhecimento importa em uma resposta afirmativa e pública que se dá ao outro. Enriquez (1990) coloca a questão em termos de desejo e de pulsão, esclarecendo que é este viés pulsional "que imprime um movimento ao organismo, mas, ao mesmo tempo, visa ao outro como aquele que pode reconhecer o desejo ou responder ao desejo de reconhecimento." (Enriquez, 1990, p. 17). Uma questão permanece posta nos CREAS e diz respeito ao reconhecimento de trabalhadores cujo público são essas populações invisíveis: deveria também seu trabalho permanecer invisível? 


\section{Trabalho e Atividade a partir das Clínicas do Trabalho}

As clínicas do trabalho ganham espaço neste texto por serem bons interlocutores da psicossociologia em suas análises clínicas e críticas acerca do trabalho e dos atravessamentos institucionais que the dizem respeito. Todas essas linhas teóricas têm como interesse central o trabalho, seus processos e os sujeitos trabalhadores. Resguardadas suas nuances, nossa proposta é a de resgatar em que ponto essas leituras nos ajudam a pensar sobre os processos de trabalho que encontramos em nosso campo, os CREAS de AracajuSE.

A psicossociologia no campo de trabalho tem como objeto de investigação por excelência os conflitos que surgem no contexto institucional e organizacional e as diversas modalidades de mal-estar que se instauram. Preza por entender como estes conflitos atravessam os sujeitos, os grupos e os diversos níveis institucionais e organizacionais e estará atenta às diferentes maneiras de se lidar com eles. Tais enfrentamentos podem ser criativos ou não, bem como podem produzir violências e rupturas dos laços que sustentam as relações. O objetivo da investigação psicossociológica, portanto, é a de conhecer e compreender como se produzem as crises, mas também de auxiliá-los (os sujeitos e os grupos) em sua busca por sentido, afinal, conforme ensina Barrus-Michel (2004), toda crise é uma crise de sentido.

A psicossociologia aposta na singularidade, estando atenta à historicidade e ao atravessamento dos fenômenos organizacionais e institucionais nas produções subjetivas e grupais, bem como aos processos de mudança que geralmente acompanham as crises. Ao resgatar a teoria psicanalítica, encontra sujeitos pulsionais tomados por desejos, ilusões e sentimentos de desamparo. Daí a concepção clínica que dela se depreende (Sevigny, 1993).

Florence Giust-Desprairies (2009), aponta a importância da démarche clínica na psicossociologia. Esta não diz respeito apenas a uma maneira de colher os materiais do campo, mas trata especialmente de uma travessia que faz o pesquisador ao se questionar sobre o sujeito a partir de um processo de singularização de um imaginário social do qual ele faz parte e em cuja construção participa. Nesta perspectiva, é mister entender o sujeito em situação (Carreteiro, 1993), sempre atravessado pelo imaginário social.

A pesquisa clínica psicossociológica diz respeito a um processo de transformação e suas intervenções "consistem em escutar o que está por trás das demandas concretamente expressas, uma demanda de produção de sentido, melhor dizendo, de construção, de restauração, de apropriação das relações e do ato cooperativo nos contextos organizacionais e institucionais." (Giust-Desprairies, 2009, p. 23-24, tradução livre). 
A clínica da atividade (Clot, 2010) traz a dimensão subjetiva intimamente ligada à dimensão da ação. A palavra tem a função de fazer agir, é dialógica no sentido de abrir os horizontes do vivido para transformar a situação. Assim, em consonância com nossos objetivos metodológicos, essa perspectiva clínica nos ajuda a compreender que a atividade de pesquisa pode e deve ter como propósito também aquele de fazer falar e de, assim, fazer transformar uma situação dada.

Clot (2010) também discute a problemática do esvaziamento de sentido no trabalho. A atrofia desse "poder de agir" fragiliza os trabalhadores, suas possibilidades subjetivas de descobrir, produzir e criar, cobrando de nós, estudiosos do trabalho, compreender o que promove essa estagnação e pensar sobre as intervenções possíveis. O autor propõe que é pela via da atividade que se iluminam as possibilidades de reconstrução do sujeito que age e fala e faz lembrar a concepção energética dos investimentos pulsionais freudianos quando implica a atividade enquanto fonte de ligações renováveis e aponta para as possibilidades de fazer desligamentos e novas ligações, produzindo e construindo o novo (Clot, 2010).

Ao trabalhar sobre tais questões, o sujeito não o faz isoladamente, ele precisa contar com o seu coletivo de trabalho. Clot afirma que o desenvolvimento do poder de agir é inseparável da capacidade desse mesmo trabalhador de ser afetado, e para tal, o sujeito tem que estar em relação e possuir plasticidade (capacidade de fazer tais desligamentos e religações), devendo poder caminhar entre intelecto e sentimento, aparecendo o mal-estar e a doença tão somente quando isso não se faz possível:

Somos feitos para fabricar contextos para neles vivermos. Uma vez que esta possibilidade esteja diminuída, e principalmente se ela desaparece de modo continuado, não vivemos, apenas sobrevivemos, submetidos que estamos aos contextos profissionais, sem poder verdadeiramente nos reconhecer naquilo que fazemos. E não é raro que aí percamos a saúde antes mesmo de "fazermos" a doença. (Clot, 2013, p. 5)

Nesta esteira, trazemos Dejours. Em sua Psicodinâmica do Trabalho, o autor faz um estudo sobre a carga psíquica envolvida no trabalho que diz respeito à relação do trabalhador com a Organização do Trabalho. Quando não há um espaço de liberdade nessa relação, quando o homem não pode negociar, inventar, modular suas relações, é aí que aparece o sofrimento e a doença. A especificidade do seu estudo se dá sobre dois polos, o das relações de trabalho e o da vivência subjetiva de prazer e sofrimento no trabalho (Dejours, 2007). 
O autor desenvolve ainda o estudo das estratégias coletivas de defesa constituídas como forma de enfrentamento dos mal-estares associados ao trabalho, essas que podem se tornar um programa de ação coletiva, que ele chama de ideologias defensivas. Elas cumprem a função de evitar as defesas individuais, de constituir um campo coletivo de arranjos possíveis com a realidade, ocultando ansiedades graves e lutando contra perigos e riscos reais. Tornam-se, para tal, obrigatórias a todos que compõem o grupo, a fim de que se tornem operatórias do seu funcionamento (Dejours, 1992).

Apesar de se tratarem também de defesas constituídas com o intuito de tamponar as ansiedades, enquanto movimento compartilhado, as ideologias defensivas protegeriam o grupo de certos riscos e angústias. A despeito disso, em consonância com autores já mencionados, o autor compreende que as possibilidades de respostas coletivas, sejam elas defensivas ou não, estão reduzidas, surgindo defesas individuais, adoecimento e sofrimento como resultado da fragmentação e da falta de sentido a que aquela conduz (Dejours, 1992).

Do reconhecimento depende na verdade o sentido do sofrimento. Quando a qualidade de meu trabalho é reconhecida, também meus esforços, minhas angústias, minhas dúvidas, minhas decepções, meus desânimos, adquirem sentido. Todo esse sofrimento, portanto, não foi em vão" (Dejours, 1999, p. 34)

Enriquez (1990), psicossociólogo, também fala sobre o reconhecimento ao tomar como referência a psicanálise freudiana. Ele menciona a necessidade que o homem tem de ser reconhecido pelos seus pares, o que implica em formação de vínculo social, e de sua necessidade de reconhecer seu próprio desejo, questão de teor narcísico. Posto nesse paradoxo, também o trabalhador precisa encontrar, em sua relação com a organização, o seu lugar de sujeito desejante e o seu lugar de objeto, este sendo o seu lugar de identificação com o outro, dentro do grupo de reconhecimento (Enriquez, 1990).

Nas conceituações de Gaulejac e Hanique (2015), estudiosos da sociologia clínica, encontramos uma lógica hipermoderna que instrumentaliza os trabalhadores, tornando-os meros recursos humanos, ao mesmo tempo em que sua implicação subjetiva passa a ser exigida como critério de avaliação do seu desempenho. Paradoxalmente, ele precisa adequar-se às exigências prescritivas da instituição, o que torna condenável qualquer questionamento, visto como sinal de resistência (Gaulejac \& Hanique, 2015).

Em face dessa reflexão, Azevedo (2005) nos transporta ao contexto do serviço público brasileiro, embora deva ser ressaltado que sua 
pesquisa foi realizada no âmbito da política de saúde. Tomando a especificidade de uma suposta segurança que repousa na tão sonhada estabilidade buscada pela via do concurso público, única via legítima de alcançar um cargo público no Brasil, o que produziria sofrimento a esses profissionais?

Trata-se de um mundo profissional onde um alto grau de autonomia faz parte do processo de trabalho, detêm-se menos controle gerencial da atividade fim, sendo ao mesmo tempo atravessado pela apatia burocrática. Por outro lado, vem impondo inúmeras condições de assujeitamento: é permeado pela desqualificação pública dos trabalhadores, funcionários públicos mal remunerados, sem perspectiva de carreira, pela precariedade do vínculo do trabalho, dada a expressão do contingente de trabalhadores terceirizados, pelo baixo compromisso desses trabalhadores, pelos interesses corporativos, pelos "esquemas de trabalho", como também pela precariedade das condições de trabalho (...) tal contexto dificulta o investimento libidinal e a constituição de outro imaginário organizacional que não 0 da impotência, do conformismo, do descrédito. (Azevedo, 2005, p. 51)

Diante disso, a autora questiona-se quanto às possibilidades de investimento pelos trabalhadores nas organizações públicas, de que elas se tornem palcos de idealização e de realização dos indivíduos quando ainda prevalece o imaginário da impotência, da desvalorização e do não reconhecimento, dado o contexto geral de precarização dos vínculos trabalhistas, de desvalorização do funcionário público e das incertezas sobre suas condições de trabalho. Em face dessa conjuntura, ela é bastante crítica a uma leitura muito otimista das potencialidades da gestão pública de saúde. É preciso não ignorar a dimensão inconsciente que atravessa o sujeito e a instituição, bem como é necessário reconhecer o mal-estar social que funda a vida coletiva e a violência como elemento inevitável nas organizações. As forças unificadoras do amor (de Eros) precisam ser levadas em conta em sua relação necessária com as forças disjuntivas, de morte, de desagregação (Azevedo, 2005).

\section{As Oficinas Sócio Clínicas}

As discussões apresentadas a seguir são resultado de análises preliminares cuja base teórica e metodológica advém da psicossociologia e do método que nomeamos aqui como sócio-clínico. As oficinas sócio-clínicas da pesquisa têm caráter dinâmico e constituem uma clara tentativa de promoção de um espaço de fala, 
ao tornar visíveis as demandas dos profissionais e de suas leituras acerca do próprio trabalho e também de intervenção sobre ele.

A denominação sócio-clínica diz respeito aos objetivos buscados nos encontros, à compreensão e à articulação permanente das problemáticas de ordem social, institucional e política com aquelas de ordem subjetiva e afetiva, cujo propósito principal foi o de promoção e produção de sentidos entre os participantes. Contamos com a participação de 10 profissionais, todos servidores públicos, entre eles dois homens e oito mulheres, cinco educadores sociais, três psicólogos e duas assistentes sociais.

Ao participar das reuniões de equipe nos CREAS, a pesquisadora deparou-se com uma diversidade de queixas e questionamentos e as tomou como fontes de mal-estar e como temáticas mobilizadoras para as discussões a serem propostas nas oficinas. Cada um dos seis encontros contou com uma dessas temáticas. Foram elas: 1. identidade pessoal e laboral, com a proposta de que falassem sobre si e sobre sua relação com o trabalho; 2 . técnica, política e militância, na qual os sujeitos foram mobilizados a articular as perspectivas técnica e política no trabalho diário; 3. Fragilidades e fortalecimento de vínculos, na qual eles discutiram uma situação de precarização de vínculos institucionais; 4 . Trabalho em rede e autonomia, no qual eles abordaram seu entendimento acerca da participação dos vários atores das políticas públicas, das instituições policiais e judiciais no seu trabalho; 5 . Educadores sociais, psicólogos, assistentes sociais e seus respectivos papeis, com a proposição de uma atividade em que eles discutiram seus papeis laborais e os conflitos envolvidos em suas relações institucionais; 6. Fechamento e feedback.

A pesquisadora capturou a busca por reconhecimento como discurso que atravessou todas as oficinas, expressada ora enquanto esforço criativo e subversivo, ora enquanto obediência aos protocolos, na atuação do bom técnico, mas também como queixa de desvalorização. Esse podia ser notado pelas questões salariais, bem como em falas nas quais afirmavam só receber críticas, jamais elogios. Logo ficou claro que essa era uma questão que atravessava e que mobilizava as equipes, fosse positivamente, incentivando 0 esforço pelo desenvolvimento do melhor trabalho, fosse negativamente, a partir de um discurso resistente e reticente quanto à inutilidade dos seus esforços, dadas as condições ofertadas e a sua desvalorização constante.

Começávamos as oficinas com algum aquecimento que já mobilizasse alguns valores e sentimentos relacionados com a temática/problemática do dia e depois partíamos para uma tarefa (cf. Pichon-Rivière, 1997) relacionada ao seu trabalho cotidiano, com o intuito de provocá-los a discutiras questões previamente apontadas por eles mesmos. 
O caráter técnico geralmente era o primeiro mobilizado, afinal, tratava-se de uma tarefa que se reportava ao seu trabalho. O grupo começava organizando as ideias a partir da sistematização de suas ações e dos fluxos. Em continuação à atividade, eles sempre adicionavam complicadores, como se quisessem produzir ali um espaço de trocas com os colegas, para tirar dúvidas sobre como proceder em uma situação específica e mais complexa. O caráter político do seu papel surgia a respeito de como lidar com certos órgãos da rede de atendimento, considerados omissos ou passivos diante das violências, mas também acerca dos posicionamentos esperados deles mesmos em determinada situação. Ainda demandavam poder de decisão e a valorização de suas possibilidades de enfrentamento das questões.

Neste ínterim, surgiu uma preocupação com a manutenção e o respeito aos vínculos familiares e com a centralidade de seu papel em relação ao acolhimento das famílias. Trouxeram, neste ponto, a questão da afetividade. Ela estaria relacionada ao fator humano que tanto os trabalhadores quanto os usuários trazem ao trabalho. Esta dimensão foi alçada a valor primordial no trabalho, embora sempre articulada a suas dimensões técnicas e políticas.

\section{Questões Analíticas: Demanda de Reconhecimento pelo Outro e Validação de seus Papeis}

Destacamos a questão do reconhecimento a partir de três linhas, ou subcategorias, a da oposição entre o prescrito e o real do trabalho, 0 conflito entre autonomia e heteronomia e a demanda de reconhecimento enquanto sujeito desejante, portador de afetividade.

\section{Astúcia e Angústia Face ao Prescrito e ao Real do Trabalho}

Ao tratarmos da problemática do trabalho, inevitavelmente nos deparamos com a oposição entre a prescrição que é feita sobre a realização das tarefas e o real manejo das situações que surgem no cotidiano de trabalho. Em nosso campo não poderia ser diferente. Há, neste caso, uma série de documentos e normativas oficiais, elaboradas em sua maioria em âmbito federal, que estabelecem as regras de execução municipal do trabalho, desde os valores que the fundamentam, até, por vezes, os protocolos de ação. Na fala dos sujeitos pesquisados, tal problemática é amplamente associada à interconexão de vários vieses, quais sejam técnico, político e afetivo. o primeiro associado ao que está prescrito na política e ao que o profissional estudou durante sua formação e continua estudando para o seu aprimoramento. O segundo carrega consigo o histórico de 
construção da política pública, enquanto o terceiro diz respeito à relação que estabelecem entre si e com os usuários.

Dissemos acima que é imprescindível alguma subversão da parte do trabalhador, ou melhor, uma invenção sobre o prescrito de forma a fazer face ao real do trabalho, geralmente impositivo e impossível de realizar. Dejours (1999, p. 30) afirma que, havendo “(...) uma defasagem irredutível entre a organização prescrita do trabalho e a organização real do trabalho (...) é impossível, nas situações comuns de trabalho, cumprir os objetivos da tarefa respeitando escrupulosamente as prescrições, as instruções e os procedimentos...". A isso ele chama de "inteligência astuciosa" (Dejours, 2007, p. 133). Tal inteligência, entretanto, não sobrevive em isolamento: ela precisa ser validada socialmente, reconhecida seja pelos pares ou pela hierarquia de trabalho, produzindo ligações com as condições psicológicas e sociais da sublimação (Dejours, 2007). A astúcia desse trabalhador pode ser entendida como uma ou a única - estratégia possível para fazer face ao sofrimento do trabalho impossível de ser realizado ou, nesse caso, para fazer face ao trabalho que não dá em nada, ao trabalho descrito eventualmente pelos profissionais como o de enxugar gelo.

O sentimento que atravessa as falas de nossos sujeitos, na maior parte do tempo, é o da impotência, mais relacionada aos resultados não alcançados ou, mais precisamente, ao não reconhecimento acerca da efetividade do seu trabalho, o que leva ao cansaço, um sentimento de muito tentar, de muito fazer, de muito laborar (cf. Arendt, 1995), em um trabalho que se consome em si mesmo, sem deixar produtos ou resultados.

Em todos os momentos, todas as pessoas, todo mundo sabe o que tem que ser feito. Sabe os encaminhamentos que têm que ser tomados, mas cada um tem uma interpretação (...) Porque no meu entendimento aquilo era melhor ou era o que eu achava. A mesma coisa é que todo mundo sabe qual é o passo a passo, mas mesmo sabendo a gente sabe que mesmo seguindo aquele passo, a gente não vai chegar ao objetivo final, entendeu? (Rita)

(...) às vezes a gente encontra as pessoas em situação de rua e o nosso primeiro impulso é de "o que é que eu vou fazer? O que é que vai resolver? Eu quero tirar da rua" e às vezes não é o que a pessoa quer naquele momento e às vezes a gente acha que tá fazendo o melhor para aquela pessoa e nem sempre esse melhor que eu acho é o que é melhor para ela. (Elis)

Aqui as prescrições não dão conta das exigências do trabalho ou das necessidades dos usuários. Aliás, há um conflito permanente a 
respeito das implicações da efetivação do seu trabalho, especialmente diante do real do trabalho trazido pelas subjetividades dos usuários e dos próprios trabalhadores, este que só pode ser manejado pela via da escuta daquele sujeito, o usuário, e da mediação no coletivo de trabalho.

Bendassoli (2012, p. 42) afirma que "trabalhar é superar a lacuna entre o prescrito e o real; é o que o sujeito deve acrescentar às prescrições para poder alcançar os objetivos que lhe são designados:". Ele acrescenta, sobre isso, que "(...) o reconhecimento pela mediação do outro e pela inscrição do sujeito numa história coletiva permite a passagem do sofrimento, inerente ao confronto com o real, ao prazer, uma vez que dá sentido a este confronto.". Com isso, o autor indica o problema e sua solução: se a atividade impedida (cf. Clot, 2013) diz respeito ao desejo de ação impedido pela falta de sentido, pela amputação do "poder de agir" do trabalhador, é o reconhecimento mediado do enfrentamento do real que permite passar do sofrimento ao prazer, da estagnação à possibilidade de atividade.

De forma mais afirmativa, Dominique Lhuillier (2009) indica que o trabalho social cobra do profissional sua transgressão: "A transgressão obriga a um duplo <<trabalho>> que vem se juntar à tarefa: um trabalho de dissimulação e um trabalho de simulação. Dissimular a não conformidade às prescrições, simular sua efetuação." (Lhuillier, 2009, p. 53).

A questão mais explicitamente relacionada ao reconhecimento do seu trabalho se coloca diante de um evidente paradoxo: há exigências técnicas escritas que sustentam ser a prioridade daquela política o trabalho em rede, daí a necessidade de comunicação entre os diversos órgãos das várias políticas públicas, e ao mesmo tempo há um formulário mensal que contabiliza atendimentos e quantifica/avalia seu trabalho que parece Ihes cobrar outra atuação:

(...) tem uma situação que vai acontecer, que eu acho que já está começando a acontecer, que se as equipes não começarem a atentar sobre isso... é o seguinte: esse RMA, ele não coleta todos os dados do que as equipes estão fazendo. (...) muitas coisas que a gente tá fazendo, que as equipes fazem não está sendo contabilizada. E aí o que é que acontece daqui a pouco número vai ficar muito baixo e vai ter uma cobrança da secretaria diante desse número. (...) as visitas institucionais elas não são computadas, as articulações não são contabilizadas. Então quando você chega para montar aquela planilha do mês, aquele caso, aquele grupo ele fez 10 visitas domiciliares, mas ela fez 20 institucionais e isso não é para contar. (Marisa) 
Queixam-se, então, da cobrança por números. Esta parece menosprezar o viés qualitativo do trabalho e os coloca face a um paradoxo da organização: pede-se a excelência de resultados, solicita-se a realização de um trabalho em rede a fim de levar em conta a história dos usuários e de suas famílias, no entanto nos protocolos de avaliação não lhes é possível sequer indicar essa dimensão. Todo empenho relacional passa a ser inviabilizado. A problemática do reconhecimento tem aqui uma dimensão burocrática. É reconhecido aquele que produz mais dados quantitativos, a despeito dos objetivos prescritos e dos entraves que inviabilizem o trabalho real. Como consequência disso, há aqueles que respiram aliviados quando, diante das cobranças, podem dizer que já fizeram tudo o que podiam:

o que me remete a essa cobrança, é aquela coisa de que a gente tem que atender, que cumprir todos os protocolos porque quando chega a cobrança "você já fez isso, você já fez aquilo? Você já fez aqui?" Aí você faz "não, já fiz tudo que eu podia fazer! Pronto! Ufa!" (Elis)

Ao longo dos encontros essa discussão foi bastante pungente, aparecendo como uma queixa do não reconhecimento, uma obrigação de cumprir as ordens que vêm "de cima pra baixo", um sentimento de incompreensão quanto à realidade do trabalho. Somos remetidos ao texto de Dejours (2007), quando ele aponta que o sofrimento no trabalho surge diante da falta de liberdade e de inventividade, que podem ser efeitos imediatos do sentimento de ter que cumprir o protocolo para, ao menos, poder contar com a justificativa de ter feito o que pôde.

A demanda constante para que haja maior clareza acerca de modos de fazer e por mais protocolos mais próximos da realidade do trabalho parece responder a uma necessidade de segurança, ou seja, que os faria sentirem-se mais capazes de responder às cobranças. Estas, típicas de uma configuração hipermoderna de sociedade e de trabalho, conforme indicamos a partir de Gaulejac \& Hanique (2015), são geralmente postas como injunções paradoxais, em que os interlocutores são submetidos a duas exigências incompatíveis e às quais eles devem obrigatoriamente responder (Gaulejac \& Hanique, 2015 , p. 13), e dizem respeito diretamente aos modos de relação e de produção capitalistas e produtivistas no campo do trabalho. A existência desses novos protocolos, que contemplassem o trabalho efetivamente feito, talvez Ihes fizessem sentirem-se mais capazes de realizar seu trabalho e, assim, de obter o reconhecimento hierárquico desejado. 


\section{Sobre Autonomia: Entre o Desejo de Liberdade e a Segurança dos Protocolos}

Enquanto a demanda por protocolos e por espaços de formação traz à baila a questão técnica em seu caráter mais puro, como se fosse possível tal pureza, a discussão sobre autonomia parece encaminhar o debate para o viés político da atuação dos profissionais, já que discutem sua atuação no sentido do "posicionar-se" e "assumir o risco" de fazê-lo, seja em termos de subversão das ordens dos que estão acima deles hierarquicamente, seja enquanto enfrentamento às exigências externas e a compreensões polissêmicas do objetivo do seu trabalho, comumente atribuídas aos órgãos judiciais e policiais.

(...) eu acho que a gente tem autonomia. Eu acho que a gente sempre tá no processo de busca por sempre ter autonomia. (...) aí eles não percebem o limiar do que a gente trabalha, do nosso atendimento, de quem é que a gente assiste. $E$ aí tem a autonomia, só que a autonomia da gente ela é meio que velada. (Marisa)

A discussão sobre autonomia aparece também como resultado da constituição de uma coletividade, ainda que ela não pareça ainda consolidada. Lembremos aqui de Lhuillier (2009) quando ela nos permite pensar acerca da importância do reconhecimento mútuo entre os colegas como forma de sustentação do valor do seu trabalho. Segundo ela nos faz refletir, o reconhecimento de si no trabalho e entre seus pares pode ser ainda mais importante que 0 reconhecimento social pensado a partir do valor social dado à função desempenhada.

(...) a gente só consegue ter mais autonomia quando a gente se fortalece com os colegas, né? Com, com... Então, por exemplo, se chega uma coisa e a gente conversa, é assim, a gente tem que falar assim, pra a gente conversar igual (...). A autonomia da gente é quando ela é coletiva, né? (Cássia)

A constatação sobre a única possibilidade de autonomia posta em forma de interrogação revela o impasse ao qual aludiu Azevedo (2005) quanto à produção social e organizacional de sujeitos heterônomos. Segundo ela, suas ações não dizem respeito a suas vontades e convicções e as possibilidades de construção de estratégias de enfrentamento coletivo tornam-se extremamente reduzidas, enquanto a exigência contemporânea do trabalho colocase em termos de autonomia e independência.

Tanto é assim que os profissionais sequer concordam todos com o uso do conceito de autonomia. Há os profissionais que o 
problematizam afirmando que alguns colegas o utilizam de forma a justificar o "não fazer" como rompimento total (e talvez injustificado) do protocolo, este que teria um valor de resguardar a atuação técnica:

(...) essa coisa de autonomia... quando ela vira livre arbítrio do profissional, ela serve, inclusive, pra quebrar instalação de protocolo, porque às vezes o protocolo que vai nos resguardar, né? (...) a galera fica "mas eu não quero instalar protocolo porque isso fere a minha autonomia técnica" que é uma discussão que é muito complicada de autonomia como fazer o que quer e não é. (Raul)

Há os protocolos e um fluxo estabelecido tecnicamente para a resolução das questões encontradas, mas há também o elemento humano, seja da parte dos profissionais, seja da parte do que cada usuário e suas famílias trazem como demanda e para o trabalho.

\section{Ser Reconhecido enquanto Sujeito: Reconhecimento, Responsabilidade ou Fardo?}

Por vezes, os trabalhadores acreditam haver uma forma para resolver a questão a partir da perspectiva de sua história pessoal, por vezes sentem-se mobilizados e impelidos a lutar em nome dos usuários que atendem. Outras vezes, eles acreditam que estão solidamente sustentados por um fluxograma que orienta os caminhos a seguir. Em outros momentos, ainda, percebem que a demanda que parte do usuário não diz respeito a nada disso, e não podem ser resolvidas a partir da perspectiva técnica nem da perspectiva política, mas que precisam de tempo para construir vínculos. Essa dificuldade foi posta diante do resultado final do suporte com o qual trabalhamos em uma das oficinas:

Eu gosto como tá pintado porque mostra também como o negócio é zuado. No melhor sentido possível, assim, é uma zona, por que a gente tem duas maneiras de fazer isso: uma que eu acho que é nisso de pensar no organograma dentro do SUAS, ou seja, das redes de proteção, como você vai encaminhando os fluxos pra além da história, né, ou seja, independente da história daquela família, qual é o fluxo dos serviços e aí o CREAS nesse papel de proativo em relação ao que tá aqui e outra que é onde começa a bagunça, no melhor sentido possível, é quando a gente começa a inserir a história dessas pessoas. (Raul) 
Este participante aponta novamente o que é invisibilizado no julgamento do trabalho. Não se pode tratar o usuário como mais um, cada um tem a sua historia particular e para que os encaminhamentos possam ter algum sucesso é importante construir vínculos. Estes necessitam de uma relação de confiança, requerem um trabalho institucional, em rede. Esta questão pode ser aproximada do que Clot (2013) denomina "fazer um trabalho bem feito".

Marca-se a importância de ter uma referência, um organograma ou um fluxograma que oriente os caminhos a serem seguidos, mas esses são sempre frios, porque preestabelecidos. É importante marcar aqui o uso do termo "zuados" pelo participante: ele diz respeito ao atravessamento da história do usuário enquanto sujeito, da sua história familiar, dos seus grupos de pares, das suas relações com as instituições, etc., que tornam impossível manter a previsibilidade que os protocolos pretendem garantir. Tudo muda quando se começa a pensar na história de cada família, nas possibilidades de diálogo entre profissionais, seja internamente ou com os equipamentos da rede:

(...) a saúde com a função de cuidar da saúde, o CRAS com a função de fazer prevenção, o CREAS com a função de reparar ou de superar uma violação e por aí vai. Cada um tem a sua especificidade, mas isso de fato só se efetiva na relação com os outros. (...) às vezes a gente fica falando desses lugares, desses equipamentos, cada um cumprindo sua função e um atrapalhando o outro, nessa coisa de não se comunicar... no exercício tem isso, né? (Raul)

A questão do reconhecimento não aparece apenas em relação àqueles que estão hierarquicamente acima, que recebem a reclamação de nunca elogiar e só cobrar, mas há também uma preocupação em serem reconhecidos pelos usuários e pelos seus pares. No caso dos últimos, parece se estabelecer um sentimento compartilhado de serem eles os que carregam o fardo mais pesado. Na mesma tarefa avaliada acima, o CREAS ficou centralizado tanto na imagem construída na oficina quanto em sua função pressuposta de responsável pelo acionamento dos outros órgãos, e também de mobilizá-los, de fazê-los dar respostas, de acompanhar as famílias, acolhendo-as e atendendo as suas demandas:

(...) fica parecendo que no CREAS é que ali tudo vai fluir e isso acarreta muita responsabilidade pra uma instituição. (Rita)

(...) na minha opinião, cabe sim o CREAS no centro não como uma proposta de ele estar resolvendo tudo, mas como uma proposta de ser serviço de referência, no caso da família de tá 
lá mesmo, sabe? Por que há um direito violado, e é por lá que tem que entrar. Agora, assim, não é dizer que ele vai tomar conta de todas as demandas daquela família, mas o CREAS tem que estar no centro. (Carlos)

A afetividade entra em jogo, então, junto à menção do fator humano. A presença de usuários, com suas histórias e demandas, e a existência de profissionais que são, eles mesmos, humanos, com desejos, sentimentos e valores pessoais. A demanda por formação é feita como se esta pudesse blindar o sofrimento e é aqui entendida, na verdade, como demanda por escuta e por um espaço de fala. $O$ que se demanda, de fato, é o seu reconhecimento enquanto sujeito pulsional que, instado a reconhecer o desejo do outro, quer ter o seu desejo também reconhecido pelos outros (cf. Enriquez, 1990). Eles solicitam, pela via da demanda por sentido, que sejam reconhecidas também as suas histórias, seu desamparo e seu sofrimento ao ter que lidar cotidianamente com a miséria e com a violência:

(...) Por que eu sempre fico avaliando: Por que é que eu to aqui? O que é que eu to fazendo? Qual é o sentido? Se a gente for parar pra pensar é a questão do cuidado com o trabalhador, tudo o que a gente fala, pra mim remete ao cuidado com o trabalhador... a gente trabalha na especial... Estou falando da especial, a gente trabalha na especial com temas que... Nós somos humanos, antes de sermos trabalhadores, de sermos profissionais, nós somos humanos. Se a gente não estiver bem, se o trabalhador não estiver bem, a gente não tem como desempenhar um papel bom. (Elis)

\section{Considerações Finais}

O reconhecimento tem uma gama muito grande de espectros. Este texto abordou, a partir da análise das práticas dos trabalhadores dos CREAS em Aracaju-SE, o reconhecimento na vertente mais negativa, ou seja, o sentimento de ser pouco reconhecido em vários níveis. Pelos superiores hierárquicos, pelos pares ou pelos usuários do serviço. Em relação aos primeiros, as críticas são mais contundentes em razão de perceberem suas ações de trabalho totalmente desconhecidas ou pouco valorizadas pelos superiores.

Isso pode produzir no trabalhador o sentimento de impotência, dando-Ihe a ideia de que não importa o quanto se esforce que ele não vai alcançar (bons) resultados com seu labor. A afirmação que fecha nosso texto parece-nos, portanto, consistente com as teorias aqui trabalhadas e com nossas análises. Sentir-se pouco ou nada valorizado, não reconhecido pelo trabalho ou pelos esforços que são 
empregados para realizá-lo, produz uma série de efeitos que ressoam no resultado final do trabalho.

O sentimento de impotência, no entanto, ainda que produza sofrimento, pode permitir tirar um fardo de si, já que parece ser menos sofrível sentir-se impotente que incompetente. Por outro lado, aquele que apesar de todos os impedimentos continua lutando, se identifica e pode ser visto pelo grupo a partir da figura do herói que luta até o fim por uma causa maior. Ele sabe que pode cumprir a prescrição, que precisará subvertê-la para realizar seu trabalho tendo a ética como princípio. Ele acredita que há pessoas que dependem do seu trabalho e que sua luta promove a proteção dos usuários e muitas vezes podem se sentir reconhecidos por estes. Esses trabalhadores também criticam os que exercem suas funções de modo burocratizado. Por outro lado, demandam mais prescrições, buscando, assim, maior segurança no exercício do seu trabalho, e quiçá até mesmo maior reconhecimento.

As estratégias de enfrentamento ao sofrimento e aos impedimentos no trabalho relativos ou decorrentes da falta de reconhecimento podem ser individuais e coletivas e aqui indicamos sua relação com três vieses: o técnico, o político e o afetivo. Só é possível subverter o prescrito quando se tem conhecimento técnico sobre ele, no entanto é também imprescindível que haja a mediação do outro, seja politicamente (como suporte para fazer junto ou para não fazer), seja afetivamente, em relação aos vínculos que se constroem.

No campo do trabalho, o exercício da autonomia requer o conhecimento do campo e a compreensão técnica do trabalho. A autonomia e a potência de agir se associam para produzir formas de ação que possam subverter o prescrito, mas ao mesmo tempo construir novos encaminhamentos de trabalho que assumam o risco de poderem ser inovadores.

\section{Referências}

Arendt, H. (1995) A Condição Humana. Rio de Janeiro: Forense Universitária.

Azevedo, C. (2005). Sob o Domínio da Urgência: o Trabalho de Diretores de Hospitais Públicos do Rio de Janeiro (Tese de Doutorado). Instituto de Psicologia da Universidade de São Paulo, São Paulo, SP.

Barus-Michel, J. (2004). O sujeito social. Belo Horizonte: Ed. PUCMinas.

Bendassoli, P. F. (2012). Reconhecimento no Trabalho: Perspectivas e Questões Contemporâneas. Psicologia em Estudo, 17(1), p. 37-46. Recuperado de http://www.scielo.br/pdf/pe/v17n1/v17n1a04.pdf 
Carreteiro, T. (1993). Contribuições da abordagem clínica ao estudo da cidadania (Tese de Concurso de Professor Titular). Universidade Federal Fluminense, Niterói, RJ .

Carreteiro, T. (1999). A doença como projeto: uma contribuição à análise de formas de filiações e desfiliações sociais. In B. B. Sawaia (Org.), As artimanhas da exclusão: análise psicossocial e ética da desigualdade social (pp. 87-96). Petrópolis: Vozes.

Carreteiro, T. (2014). A escolha da função pública como campo de emprego para jovens adultos. Cadernos de Psicologia Social do Trabalho, 17(spe.1), 85-96. doi:10.11606/issn.19810490.v17ispe1p85-96

Clot, Y. (2010). Questões de Ofício (Introdução). In Y. Clot, Trabalho e Poder de Agir. Belo Horizonte: Fabrefactum.

Clot, Y. (2013). O ofício como operador de saúde. Cadernos de Psicologia Social do Trabalho, 16(esp.1), 1-11. Recuperado de http://pepsic. bvsalud.org/pdf/cpst/v16nspe/v16ns1a02.pdf

Dejours, C. (1992). A Loucura do Trabalho: Estudo de Psicopatologia do Trabalho. São Paulo: Cortez-Oboré.

Dejours, C. (1999) A Banalização da Injustiça Social. Rio de Janeiro: Editora Fundação Getúlio Vargas.

Dejours, C. (2007). Psicodinâmica do trabalho, contribuições da Escola Dejouriana à análise da relação prazer, sofrimento e trabalho. São Paulo: Atlas.

Enriquez, E. (1990). Da Horda ao Estado: Psicanálise do Vínculo Social. Rio de Janeiro: Zahar.

Gaulejac, V., \& Hanique, F. (2015). Le Capitalisme Paradoxant: Unsystème que rendfou. Paris: Le Seuil.

Giust-Desprairies, F. (2009). L'imaginaire collectif. Toulouse: Éditions érès.

Honneth, A. (2001). Recognition: Invisibility: On The Epistemology Of 'Recognition'. The Aristotelian Society Supplementary, 75(1), 111-126. doi: 10.1111/1467-8349.00081

Lhuillier, D. (2005). Le "sale boulot". Revue Travailler.Paris: Martin Média.

Lhuillier, D. (2009). Travail Du négatif, travail sur Le négatif. Education PermanentE, (179).

Pichon-Rivière, E. (1997). El Proceso Grupal: Del psicoanálisis a la psicologia social (1). Argentina: Nueva Vision.

Sevigny, R. (1993). L'approche clinique dans les science humaines. In E. Enriquez, G. Houle, J. Rhéaume, \& R. Sevigny (Dir.), L'analyse Clinique dans les sciences humaines. Montréal: Éditions Sait-Martin. 


\section{Endereço para correspondência}

\section{Carolina Rodrigues Alves de Souza}

Rua B, 300, Loteamento Santa Clara, Bairro Aeroporto, CEP 49037-713, Aracaju SE, Brasil

Endereço eletrônico: carolinarodriguesalves@gmail.com

\section{Teresa Cristina Othenio Cordeiro Carreteiro}

Rua Figueiredo Magalhaes, 285 / 401, Copacabana, CEP 22031-011, Rio de Janeiro - RJ, Brasil

Endereço eletrônico: tecar2@uol.com.br

Recebido em: 13/09/2018

Reformulado em: 07/02/2019

Aceito em: 09/02/2019

\section{Notas}

* Psicóloga, graduada em Psicologia e Mestre em Psicologia Social pela Universidade Federal de Sergipe (UFS), especialista em Direitos Infanto-J uvenis pela Universidade Aberta do Brasil (UAB/UFS) e Doutoranda em Psicologia pela Universidade Federal Fluminense (UFF).

** Professora Titular do Programa de Pós-graduação em Psicologia, UFF, Pesquisadora do CNPq.

1 Esta pesquisa foi submetida ao Comitê de Ética da Universidade Federal Fluminense e aprovada com número CAAE 49303715.6.0000.5243. O presente trabalho foi realizado com apoio da Coordenação de Aperfeiçoamento de Pessoal de Nível Superior-Brasil (CAPES) - código de Financiamento 001.

Este artigo de revista Estudos e Pesquisas em Psicologia é licenciado sob uma Licença Creative Commons Atribuição-Não Comercial 3.0 Não Adaptada. 